\begin{tabular}{|c|c|}
\hline Title & $\begin{array}{l}\text { Comparisons of O-acylation and Friedel-Crafts acylation of phenols and acyl chlorides and Fries rearrangement of } \\
\text { phenyl esters in trifluoromethanesulfonic acid: effective synthesis of optically active homotyrosines }\end{array}$ \\
\hline Author(s) & $\begin{array}{l}\text { Murashige, Ryo; Hayashi, Y uka; Ohmori, Syo; Torii, Ayuko; A izu, Y oko; Muto, Y asuyuki; Murai, Y uta; Oda, Y uji; } \\
\text { Hashimoto, Makoto }\end{array}$ \\
\hline Citation & $\begin{array}{l}\text { Tetrahedron, 67(3), 641-649 } \\
\text { https://doi.org/10.1016/.tet.2010.11.047 }\end{array}$ \\
\hline Issue Date & 2011-01-21 \\
\hline Doc URL & http:/hdl.handle.net/2115/44794 \\
\hline Type & article (author version) \\
\hline File Information & T revised 09Nov10-2.pdf \\
\hline
\end{tabular}

Instructions for use 


\section{Graphical Abstract}

To create your abstract, type over the instructions in the template box below.

Fonts or abstract dimensions should not be changed or altered.

Comparisons of O-acylation and Friedel-

Crafts acylation of phenols and acyl

chlorides and Fries rearrangement of phenyl

esters in trifluoromethanesulfonic acid:

Effective synthesis of optically active homotyrosines

Ryo Murashige, Yuka Hayashi, Syo Ohmori, Ayuko Torii, Yoko Aizu,

Yasuyuki Muto, Yuta Murai, Yuji Oda, Makoto Hashimoto*

Department of Agricultural and Life Science,

Obihiro University of Agriculture and Veterinary Medicine

Leave this area blank for abstract info.

Division of Applied Science, Graduate School of Aqriculture, Hokkaido University 


\title{
Comparisons of O-acylation and Friedel-Crafts acylation of phenols and acyl chlorides and Fries rearrangement of phenyl esters in trifluoromethanesulfonic acid: Effective synthesis of optically active homotyrosines
}

\author{
Ryo Murashige $^{\mathrm{a}, \mathrm{b}}$, Yuka Hayashi ${ }^{\mathrm{a}}$, Syo Ohmori ${ }^{\mathrm{a}}$, Ayuko Torii ${ }^{\mathrm{a}}$, Yoko Aizu ${ }^{\mathrm{a}}$, Yasuyuki Muto ${ }^{\mathrm{a}}$, Yuta \\ Murai ${ }^{c}$, Yuji Oda ${ }^{\text {a }}$, Makoto Hashimoto ${ }^{\mathrm{c}}{ }^{*}$ \\ ${ }^{a}$ Department of Agricultural and Life Science, Obihiro University of Agriculture and Veterinary Medicine, Inada-cho, Obihiro 080-8555, Hokkaido, Japan \\ ${ }^{b}$ Department of Pharmaceutical Sciences, Himeji Dokkyo University, 7-2-1 Kamioono, Himeji 670-8524, Hyogo, Japan \\ ${ }^{c}$ Division of Applied Science, Graduate School of Agriculture, Hokkaido University; Kita 9, Nishi 9, Kita-ku, Sapporo 060-8589, Japan
}

\section{ARTICLE INFO}

\section{Article history:}

Received

Received in revised form

Accepted

Available online

\section{Keywords:}

Friedel-Crafts acylation

Fries rearrangement

O-acylation

trifluoromethanesulfonic acid

homotyrosine

\section{ABSTRACT}

Reactions involving phenol derivatives and acyl chlorides have to be controlled for competitive O-acylations and C-acylations (Friedel-Crafts acylations and Fries rearrangements) in acidic condition. The extent for these reactions in trfluoromethanesulfonic acid ( $\mathrm{TfOH})$, which is used as catalyst and solvent, is examined. Although diluted $\mathrm{TfOH}$ was needed for effective Oacylation, concentrated $\mathrm{TfOH}$ was required for effective $\mathrm{C}$-acylations in mild condition. These results have been applied to the novel synthesis of homotyrosine derivatives. Both Fries rearrangement of $N$-TFA-Asp(OBn)-OMe and Friedel-Crafts acylation of phenol with $N$-TFAAsp(Cl)-OMe in TfOH afforded the homotyrosine skeleton, followed by reduction and deprotection afforded homotyrosines maintaining stereochemistry of Asp as an optically pure form.

2009 Elsevier Ltd. All rights reserved.

\section{Introduction}

Hydroxyaryl ketones are versatile intermediates in the synthesis of biologically active compounds and both FriedelCrafts acylation of phenol derivatives and Fries rearrangement of acyloxy benzenes are major pathways for their preparations. ${ }^{1}$ These reactions have been promoted with Lewis acid. Superacidic systems that may be formed by mixing appropriate Lewis and Brønsted acids have been the subject of much academic and industrial research. ${ }^{2}$ Trifluoromethanesulfonic acid (TfOH), which can be considered a super-acid, forms waterstable salts with non-hydrolysable metals. ${ }^{3}$ The rare-earth metal triflates are also useful for the purpose, ${ }^{4}$ but it is sometimes difficult to completely archive these reactions. We recently reported that neat TfOH catalyzed Friedel-Crafts acylation. This involved stoichiometric amounts of non-phenolic aromatics and acid chlorides at a side chain of aspartic and glutamic acid whose stereochemistry was maintained in a very mild condition. ${ }^{5}$ In the reaction, TfOH was used as a catalyst of Friedel-Crafts acylation and as a solvent for amino acid derivatives. For the phenol derivatives, it is necessary to take into account that the Oacylation and C-acylation (Friedel-Crafts acylation and Fries rearrangement) are attractive objects for synthetic chemistry
(Scheme 1). The establishment of comparisons of these reactions is necessary for applied to derivatizations of phenols used for amino acid modifications.

Homotyrosine (hTyr), as a nonproteinogenic $\alpha$-amino acid, elongates methylene in a side chain of tyrosine (Tyr). The hTyr is present as a component of diverse natural products that have important biological activities ${ }^{6}$ and its derivatives are important precursors for the total synthesis of some natural products. ${ }^{7}$ Also sometimes it produces different biological activities when resplacing Tyr with hTyr in bioactive peptides. ${ }^{8}$

Asymmetric and efficient synthesis of hTyr is important. There are several reports of the synthesis of hTyr; for example synthetic methods include: enzymatic resolution, ${ }^{6,9}$ Suzuki-coupling, ${ }^{10}$ diastereoselective Michael addition ${ }^{11}$ and catalytic asymmetric hydrogenation $^{12}$. These methods require special reagents or precursors and phenolic hydroxyl groups would not be expected to tolerate the synthesis conditions.

Furthermore, these methods require the preparation of special reagents or precursors for the asymmetric synthesis of both enantiomers. Few reports are available, involving the synthetic routes without phenolic hydroxyl protection. ${ }^{13}$ 
Amino acids are one of the most popular precursors for stereocontrolled synthesis and are easily available for asymmetric synthesis. ${ }^{14}$ The Friedel-Crafts reactions between phenol and a side chain of aspartic acid (Asp) is one of the key reactions for synthesis of optically pure hTyr enantiomers' skeletons. To our best knowledge, however, there are no studies for Friedel-Crafts between phenols and Asp derivatives. Because the $\alpha$-amino acid equivalents are insoluble to these organic solvents in the presence of Lewis acid, the reaction mixture forms a suspension.

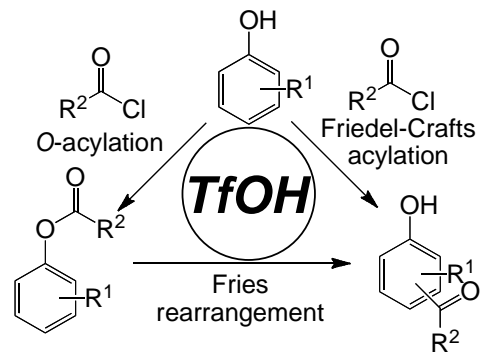

Scheme 1. Schematic relationships of the reactions of phenols and acyl chlorides, and $\mathrm{O}$-acyloxy benzenes in $\mathrm{TfOH}$.

In this paper, we report the comparisons of O- and Cacylation for the phenol reaction with acyl halides, and Fries rearrangement of phenyl ester using TfOH. Furthermore, the established conditions were applied to effective synthesis of optically pure hTyr using stoichiometric amounts of unprotected phenol and acyl chloride derivative of Asp.

\section{Results and Discussion}

\subsection{O-Acylation of phenol derivatives and acyl chlorides in the presence of $\mathrm{TfOH}$}

Dumeunier and Markó reported $\mathrm{Sc}(\mathrm{OTf})_{3}$ or TfOH catalyzed O-acetylation with three equivalents of acetic anhydride in $\mathrm{CH}_{3} \mathrm{CN}$ for alkyl alcohol. ${ }^{15}$ First, we set up reactions in which the stoichiometric amounts of phenol $\mathbf{1}$ and acetyl chloride $\mathbf{2}$ in various proportions of $\mathrm{TfOH}$ in $\mathrm{CH}_{3} \mathrm{CN}$ at room temperature were varied. The complete conversion to the $O$-acetylated product $\mathbf{3}$ is very difficult in the condition, because the starting phenol 1 remained and Friedel-Crafts type $C$-acylated product $\mathbf{4}$ was detected in the reaction mixture (Scheme 2a). It is very difficult to control the competitive reactions, O-acylation, Cacylation and hydrolysis of O-acylated compounds, under these conditions.

For complete O-acylation, three equivalents of acetyl chloride 2 were treated with a low concentration of $\mathrm{TfOH}$ in $\mathrm{CH}_{3} \mathrm{CN}$ at room temperature to prevent hydrolysis of O-acetylated product 3 and formation of $\mathrm{C}$-acylated product 4 . The complete reaction was observed at $1 \% \mathrm{TfOH}$ in $\mathrm{CH}_{3} \mathrm{CN}$. The results are in agreement with previous acetylation of alkyl alcohol using $\mathrm{TfOH} .{ }^{15}$ The higher proportion of TfOH promoted the formations of C-acetylated, 1-(4-hydroxyphenyl)-ethanone 4, and O- and Cdiacetylated, 4-acetylphenyl acetate $\mathbf{5}$, but the starting material phenol 1 was not detected when using this condition (Scheme 2b)

The optimized $O$-acetylation conditions using various acyl chlorides were applied to cresols, halophenols and naphthols with high yield at room temperature within an hour (Table 1 entries 311).

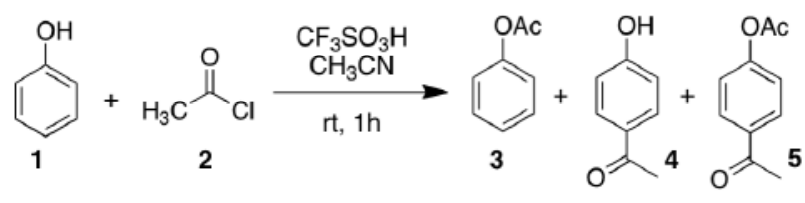

(a) One equivalent of acetyl chloride

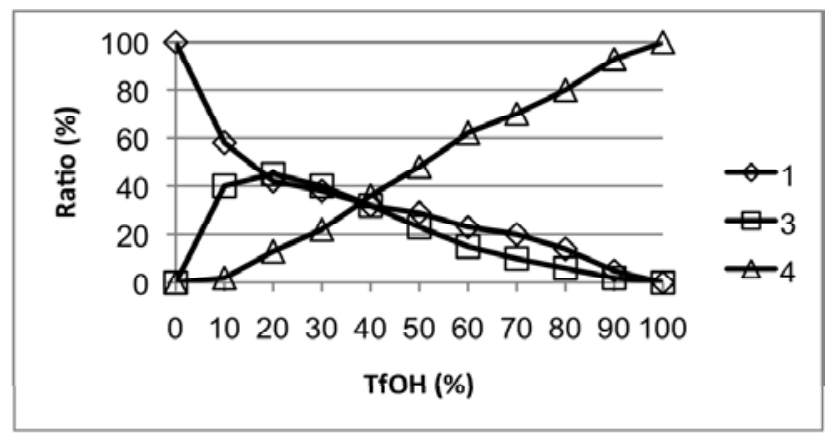

(b) Three equivalents of acetyl chloride

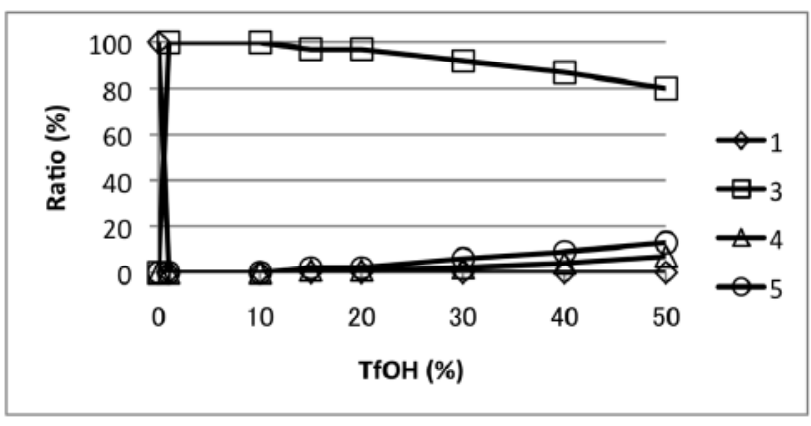

Scheme 2. Effect of TfOH proportion for acetylations. $O$ - and $C$ - acetylation of phenol 1 with 1 (a) and 3 (b) equivalent of acetyl chloride 2 . TfOH \% indicated the proportion of $\mathrm{TfOH}$ in $\mathrm{CH}_{3} \mathrm{CN}$.

\subsection{Fridel-Crafts acylation of phenol derivatives and acyl chloride in the presence of $\mathrm{TfOH}$.}

Scheme 2a also shows Fridel-Crafts acylation of phenol 1 proceeded with stoichiometric amounts of acetyl chloride in neat $\mathrm{TfOH}$ at room temperature completely within an hour. The results were consistent with our previous reports for synthesis of homo- and bishomo- phenylalanine synthesis for non-phenolic aromatics. $^{5}$ The condition can be applied to various acyl chlorides and no effects of carbon chain length were observed (Table 2, entry 1). The reactions of cresols were slightly more complicated than those for phenol. The $o$-cresol was C-acylated in various acyl chlorides at 4-position selectively within an hour (Table 2, entry 2). The $p$-cresol afforded C-acylated derivatives with regioselective at 6-position in excellent yields. The reaction time of $p$-cresol is longer than that of $o$-cresol, and is in proportion to the carbon chain length of acyl halides (Table 2, entry 3). $m$-Cresol was converted to Friedel-Crafts type products 
Table 1. $\mathrm{O}$-acylation of phenols with acyl chlorides in $1 \% \mathrm{TfOH}-\mathrm{CH}_{3} \mathrm{CN}$

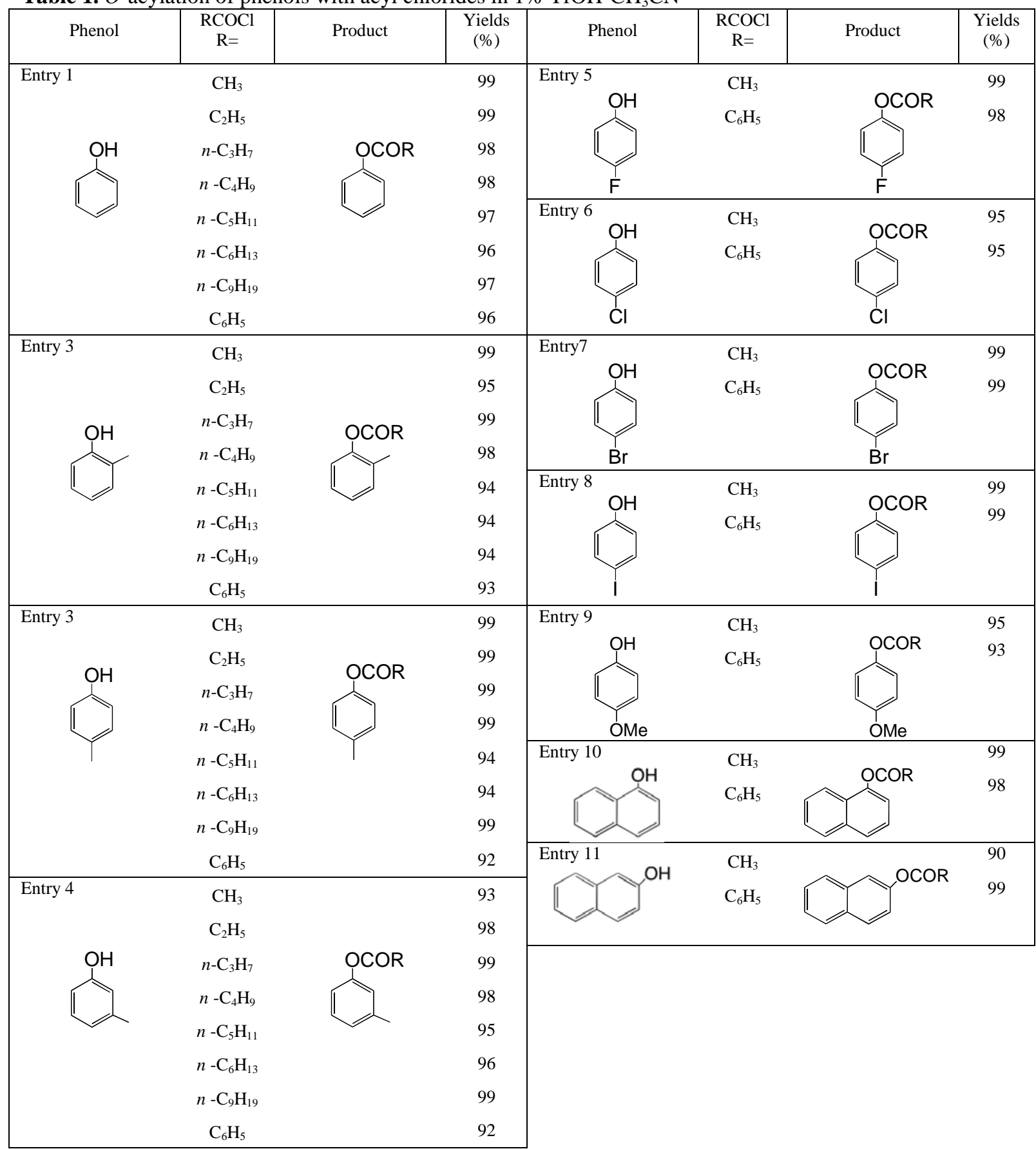

at $86 \%$ yield with stoichiometric amounts of acetyl chloride. A slightly larger amount of acetyl chloride (1.2 and 1.5 equivalents) and a longer reaction time (16 hours) improved the acylation which afforded two isomer 4- and 6- positions with 1.7 1.4 : 1 ratio. The optimized conditions can be applied to several acyl chlorides and no differences in reactivity of carbon chain length were observed (Table 2, entry 4). 4-Fluoro-, chloro- and bromophenols have to heated at $60^{\circ} \mathrm{C}$ in neat $\mathrm{TfOH}$ to achieve FriedelCrafts acetylations and benzoylations using acetyl- and benzoylchlorides in good yield (Table 2 entries 5-7). Fridel-Crafts reaction of 4-iodophenol affords a complex mixture. The yield of desired products was very low (Table 2, entry 9). p-Methoxy phenols have to be heated at $100{ }^{\circ} \mathrm{C}$ to achieve Friedel-Crafts acylations. Methoxy group was also deprotected during the reaction (Table 2, entry 10).
Friedel-Crafts reactions of naphthols with slightly larger amount of acetyl chloride (1.5 equivalent) afforded the products in good yield. The orientations of the acetyl moiety were consistent with normal orientation rules. No benzoylation of 1- or 2-naphthols were observed with stoichiometric amounts of benzoyl chloride. Ten equivalents of benzoyl chloride produced the desired products. The benzoylation of 1-naphthol afforded as sole product at 4-benzoylated product due to steric hindrance at the 2-position (Table 2, entry 10). On the other hand, 2-naphthol afforded 1- and 3- benzoylated products (20:1) under these condition (Table2, entry 11).

\subsection{Fries rearrangements of O-acyloxy benzenes}

The reactions involving Fries rearrangements of O-acyloxy benzenes with rare-earth metal triflates have been out under 
Table 2. Friedel-Crafts acylations of phenol derivatives with acyl chlorides in neat TfOH.

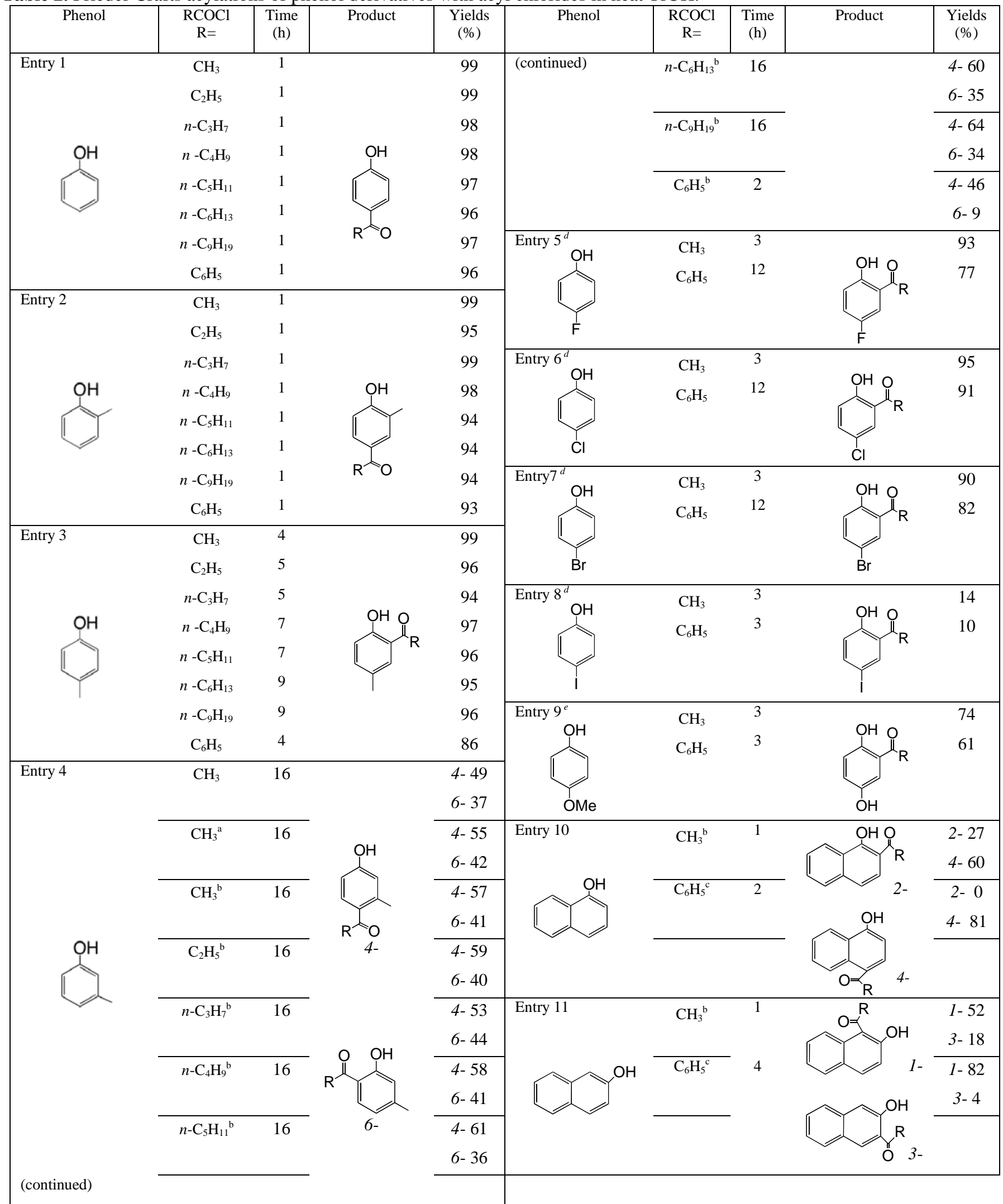

The reactions were set up equivalent of acyl halides at room temperature except perentheses. ${ }^{\mathrm{a}} 1.2$ equivalents. ${ }^{\mathrm{b}} 1.5$ equivalents. ${ }^{\mathrm{c}} 10$ equivalents, ${ }^{d}$ at $60{ }^{\circ} \mathrm{C},{ }^{e}$ at $100{ }^{\circ} \mathrm{C}$

heating conditions. ${ }^{16}$ There have been reports that combinations of rare metal triflates or phosphorous oxychloride in the presence of methanesulfonic acid were effective for Fries rearrangement, but the reaction was also carried out under heating conditions. ${ }^{17}$
The phenyl acetate $\mathbf{3}$ was subjected in various proportions of $\mathrm{TfOH}$ in $\mathrm{CH}_{3} \mathrm{CN}$ at room temperature for an hour. Both Fries rearrangement and hydrolysis of the starting material $\mathbf{3}$ was observed with less than $60 \% \mathrm{TfOH}$ in $\mathrm{CH}_{3} \mathrm{CN}$. 
Table 3. Fries-rearrangement of $O$-acyloxy benzenes and naphthalenes in neat TfOH.

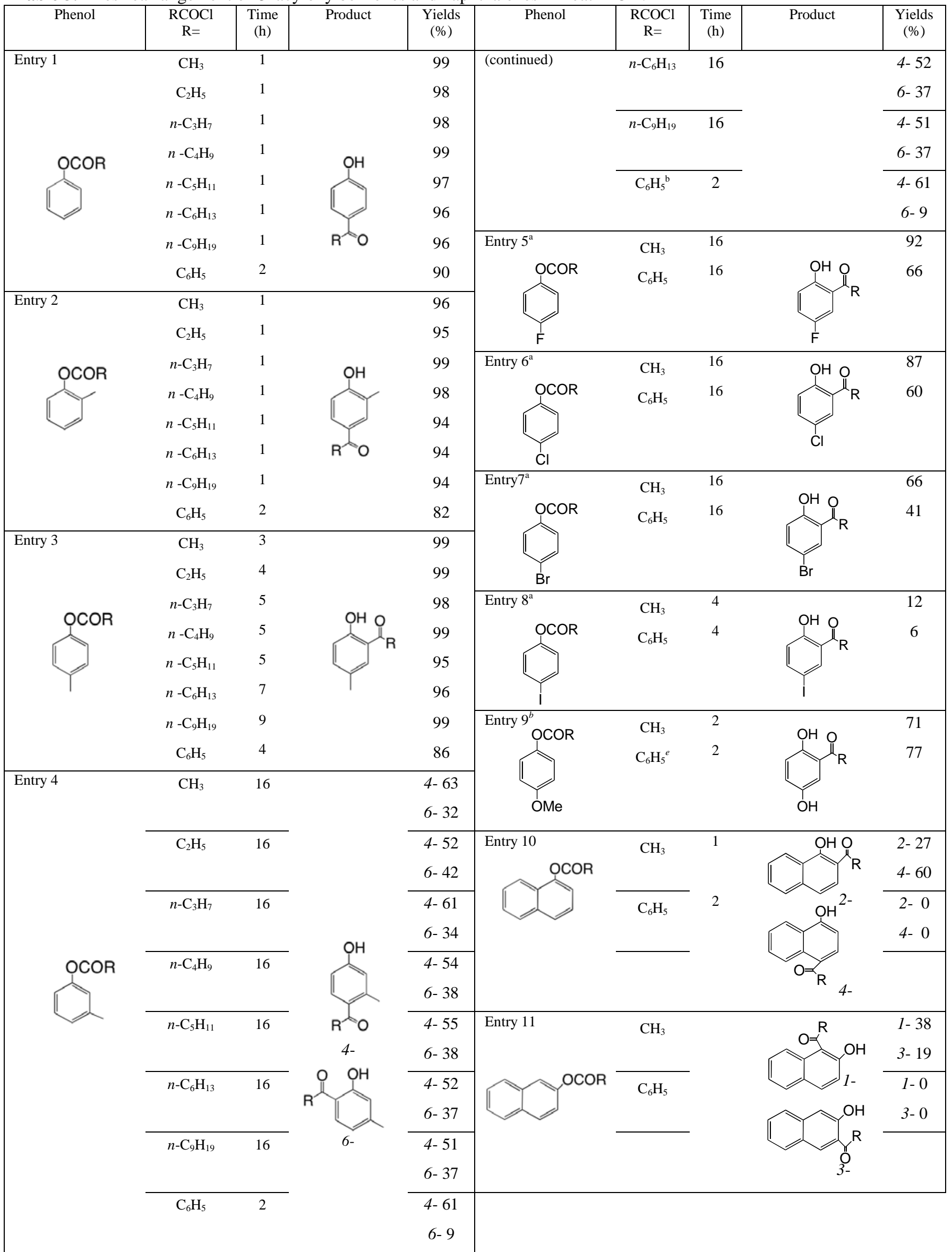

The reactions were set up equivalent of acyl halides at room temperature except perentheses. ${ }^{\mathrm{a}}$ at $60{ }^{\circ} \mathrm{C}$. ${ }^{\text {be }}$ at $100{ }^{\circ} \mathrm{C}$ 

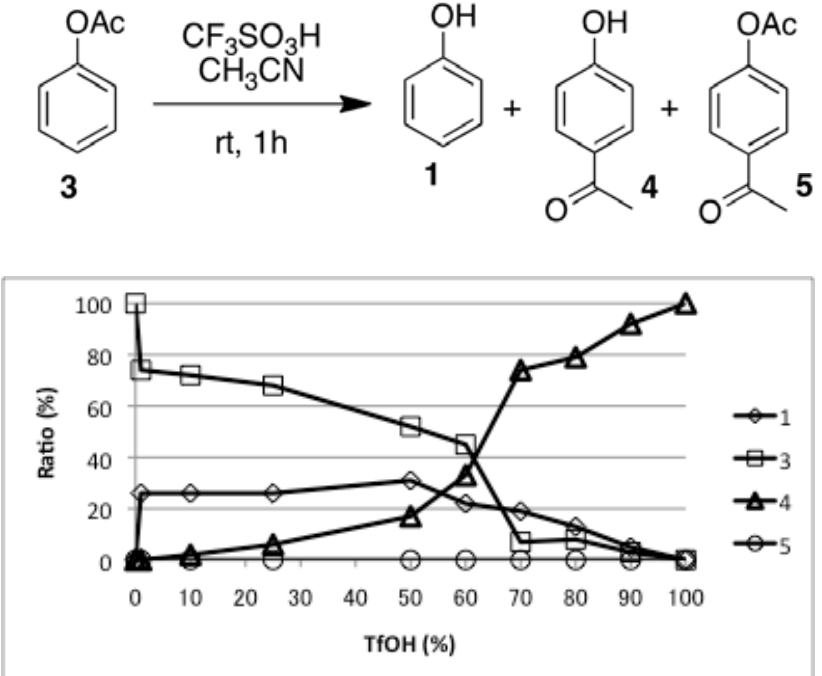

Scheme 3. Fries rearrangement of phenyl acetate (3) in various $\mathrm{TfOH}$ proportion in $\mathrm{CH}_{3} \mathrm{CN}$ for an hour.

The phenyl acetate $\mathbf{3}$ was completely rearranged to $p$ acetylphenol 4 in neat TfOH. No o-acetylphenol and 4acetylphenyl acetate 5 was observed during the reaction (Scheme 3 and Table 3, entry 1).

The rearrangement of $o$-acyloxy toluenes afforded regiospecific products, in which the acyl groups were migrated to the 4position at room temperature within an hour (Table 3, entry 2). The rearrangement of $p$-acyloxy toluene also afforded regiospecific products, in which the acyl group was migrated to the 6 -position. But the reaction time was longer than 0 -isomer identical manner described in Friedel-Crafts acylation (Table3, entry 3).

The $m$-acyloxy toluene reactions afforded a more complex mixture than that of 4- and 6- isomers (Table 3, entry 4). Although the desired 4- and 6- orientated products (predominately 4-) were detected in the reaction mixture, the hydrolysis product ( $m$-cresol) was also detected when the reaction mixture was diluted in $\mathrm{CDCl}_{3}$ directly and then subjected to ${ }^{1} \mathrm{H}-\mathrm{NMR}$ analysis. The maximum rearrangement was observed after 16 hours.

Our results indicated that the $m$-tolyl acetate $\mathbf{6}$ was subjected to both Fries rearrangement and hydrolysis. The hydrolyzed $m$ cresol reacted with an in situ generated acyl donor equivalent to a Friedel-Crafts type reaction. To support the hypothesis, the reaction of $m$-cresol 7 with stoichiometric amounts of acetic acid 8 was compared with Fries rearrangement of $\mathbf{6}$ in neat $\mathrm{TfOH}$ at room temperature (Scheme 4). Fries rearrangement of 6 (82\%) was faster than the reaction of 7 and 8 (52\%) as monitored in an hour. But 16 hours later, the yields of both reactions became almost the same. The proportions of isomers (9 and 10) did not change in any reaction time. The results indicated competitive reactions of Fries rearrangement and hydrolysis of m-tolyl acetate $\mathbf{6}$ was occurring, but the hydrolyzed acyl donor equivalent was also re-reacted with m-cresol as a Friedel-Crafts type reaction over a long reaction time.

The results are consistent with the fact that stoichiometric amounts of acetic acid $\mathbf{8}$ can act as an acyl donor for FriedelCrafts acylation of toluene in $\mathrm{TfOH} .{ }^{18}$ However, a previous study reported that mainly $o$-acylated isomer was afforded by the treatment of $m$-cresol and carboxylic acid with graphite and methanesulfonic acid at $120{ }^{\circ} \mathrm{C}$ in several hours. ${ }^{19}$ On the other hand, our conditions, which were carried out at room temperature, afforded 4- and 6- acetylated isomers with a $1.4 \sim 2: 1$ ratio. The reaction condition can be applied to various carbon chains of $m$ acyloxy toluenes in good yield (Table 3, entry 4).

4-Fluoro-, 4-chloro- and 4-bromo- phenylacetate or phenylbenzoate have to heated at $60^{\circ} \mathrm{C}$ in neat $\mathrm{TfOH}$ to achieve Fries rearrangements in good yield (Table 3 entries 5-7). Fries rearrangement of 4-iodo phenylacetate or phenylbenzoate afforded a complex mixture as monitored after for several hours and the yield of desired products was very low (Table 3, entry 9). 4-Methoxyphenyl acetate has to heat at $100{ }^{\circ} \mathrm{C}$ to achieve Friedel-Crafts acylations. Methoxy group was also deprotected during the reaction (Table 3, entry 10).

1- or 2- Naphthyl acetate also proceeded through a Fries rearrangement which consisted of a normal orientation. But 1- or 2- naphthyl benzoate did not afford the rearrangement product (Table 3, entries 10 and 11). The results are consistent with large excess benzoyl chloride (10 equivalents) being needed in direct Friedel-Crafts reactions for both naphthols.
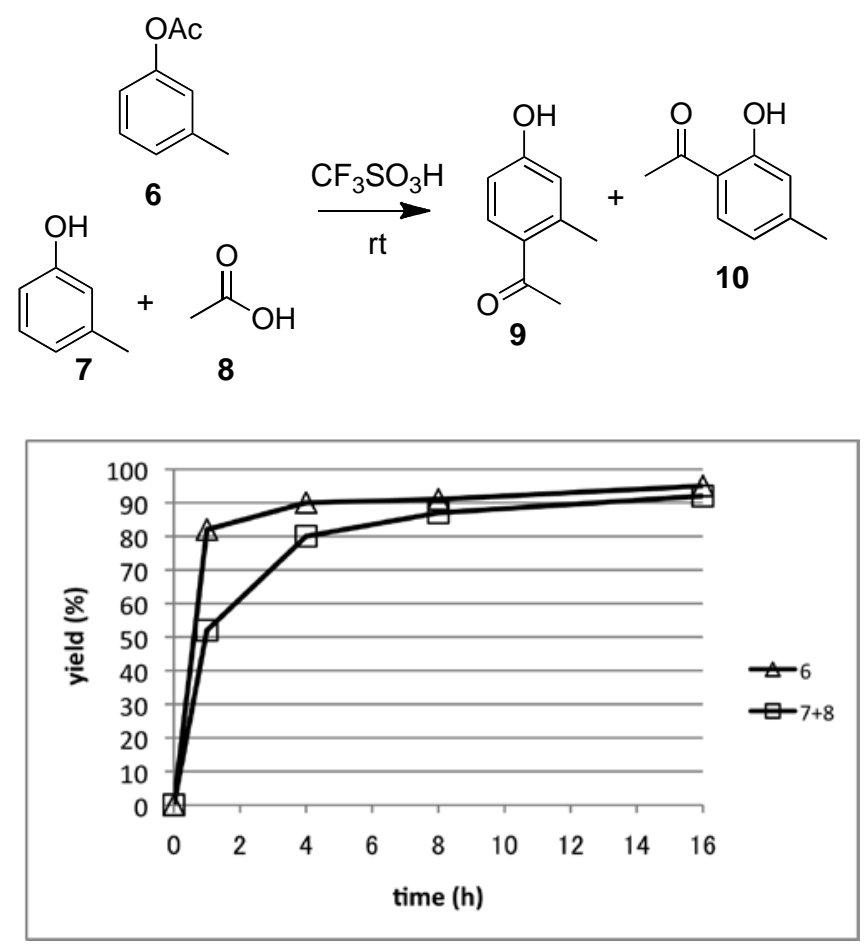

Scheme 4. Time courses of Fries rearrangement of $m$-tolyl acetate (6) and Friedel-Crafts reaction with stoichiometric amounts of $m$-cresol (7) and acetic acid (8) in TfOH at room temperature. Yield was calculated as mixtures of 9 and $\mathbf{1 0 .}$

\subsection{Synthesis of o- and p-homotyrosine}

The comprehensive studies of reactivities of phenol derivatives described above were also applied to synthesis of optically pure homotyrosine from phenol 1 without deprotection of the phenolic alcohol. Phenol 1 and three equivalents of $N$ TFA-Asp(Cl)-OMe $\mathbf{1 1}^{20}$ afforded $N$-TFA-Asp-OMe $\beta$-phenyl ester 12, which is the $\mathrm{O}$-acylated product, in excellent yield when using diluted TfOH at room temperature for an hour. The phenyl ester of amino acids has normally been prepared with carbodiimides as a promoter, and conversions have not been quantitative. 
Fries rearrangement of phenyl ester $\mathbf{1 2}$ proceeded in neat $\mathrm{TfOH}$ at room temperature for 16 hours in good yield. The rearrangement afforded two C-acylated isomers, $p$ - (13) and $o$ (14) aroylbenzene derivatives. The proportion was calculated as 1.4 : 1 for 13 and 14 , respectively.

Friedel-Crafts reaction of phenol 1 and $N$-TFA-Asp(Cl)-OMe 11 also afforded two C-acylated isomers 13 and 14 using neat $\mathrm{TfOH}$ at room temperature for an hour. The proportion of the regioisomer was almost the same. The reaction time of the Friedel-Crafts reaction was much faster than that of the Fries rearrangement. These results are identical with our findings described in scheme 4 that Fries rearrangement caused hydrolysis of phenyl ester and in situ generated acyl donor equivalent was subjected to a Friedel-Crafts type reaction.

The benzylic carbonyl of $\mathbf{1 3}$ and $\mathbf{1 4}$ were reduced to methylene with $\mathrm{Pd} / \mathrm{C}$ under the $\mathrm{H}_{2}$ atmosphere $(\mathbf{1 5}, \mathbf{1 6})$, followed by deprotection of the both protecting groups under the acidic conditions to afford optically pure (ee $>99 \%$ ) hTyr derivatives $(17,18)$ in excellent yields.

Ruth has already reported the synthesis of $o$-hTyr from kynrenine five decades ago. $^{21}$ To the best of our knowledge, few papers have been subsequently reported for the synthesis of $o$ hTyr. It is first time that the aspartic acid derivatives are introduced to phenol derivatives using the TfOH. TfOH has both catalytic activities for Friedel-Crafts and Fries rearrangements, and high solubility for the amino acid derivatives in good yield. The asymmetric center of the starting Asp derivatives in these products did not change (Scheme 5).

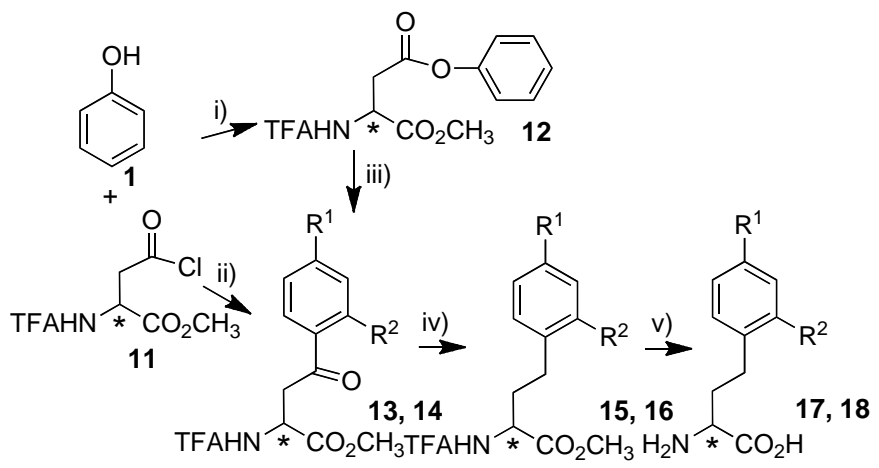

$13,15,17 \mathrm{R}^{1}=\mathrm{OH}, \mathrm{R}^{2}=\mathrm{H}$

$14,16,18 \mathrm{R}^{1}=\mathrm{H}, \mathrm{R}^{2}=\mathrm{OH}$

Scheme 5. Homotyrosine synthesis with Friedel-Crafts acylation and Fries rearrangement. i) $3 \% \mathrm{TfOH}, \mathrm{CH}_{3} \mathrm{CN}$, room temperature, $1 \mathrm{~h}, 86 \sim 91 \%$, ii) TfOH, room temperature, $1 \mathrm{~h}, 79 \%(\mathbf{1 3}: \mathbf{1 4}=1: 1)$, iii) TfOH, room temperature, 16h, 78 84 \% (13:14 = $1.4: 1)$, iv) $\mathrm{H}_{2}$, Pd/C, rt, 1h, 86 99\%, v) $6 \mathrm{~N} \mathrm{HCl}, 80^{\circ} \mathrm{C}, 6 \mathrm{~h}, 90-97 \%$.

\section{Conclusions}

The effective synthetic routes for the O-acyloxy benzenes and hydroxyaryl ketones will be very useful for synthesis of bioactive compounds. Both skeletons were available from phenol derivatives and acyl equivalents in acidic conditions. TfOH is known as a super-acid and is used as catalyst in Friedel-Crafts acylation $^{22}$ and alkylation ${ }^{23}$. The acylation mechanisms proposed are that carboxylic acid derivatives form trifluoromethanesulfonic - carboxylic anhydrides as active species $^{24}$, and then the active species reacted with the aromatics. However few reports have been issued for the reaction with phenol derivatives ${ }^{25}$. The contribution of the TfOH for $O$ acylation of phenol derivatives, Friedel-Crafts acylation with acyl chloride, and Fries rearrangement of $O$-acyloxy benzenes were examined here. Our results show controls of $O$-acylation, Friedel-
Crafts acylation and Fries rearrangement of acyloxy benzenes can be produced with TfOH proportion in $\mathrm{CH}_{3} \mathrm{CN}$. The Oacylation proceeded to completion at low concentration of $\mathrm{TfOH}$ in $\mathrm{CH}_{3} \mathrm{CN}$. On the other hand the Friedel-Crafts acylation and Fries rearrangement almost proceeded effectively in neat $\mathrm{TfOH}$. Furthermore, our strategies are very beneficial because the reaction conditions were proceeded at milder conditions than previous reports ${ }^{17,18,26}$.

These observations on control, of these types of reactions were applied to hTyr synthesis, which is not easily prepared using previous methods. Our synthetic routes produce good total yields and are easy for stereocontrolled synthesis, because optical purity of Asp derivatives can be maintained during the reaction.

The controls of O-acylation, Friedel-Crafts reactions and Fries rearrangements of phenol derivatives by $\mathrm{TfOH}$ concentrations will contribute to effective preparation of the O-acyloxy benzenes and hydroxyaryl ketones.

\section{Experimental Section}

\subsection{General}

NMR spectra were measured by JEOL ECA-500 spectrometers. IR spectra were measured by Jasco FTIR-4100 instrument. TfOH was purchased from Wako Chemicals. All solvents were of reagent grade and distilled using the appropriate methods. MS data were obtained with a Hitachi NanoFrontier LD mass spectrometer. Chiral HPLC was performed with Chirobiotic $\mathrm{T}$ (Astec), 4.6 × $250 \mathrm{~mm}$, eluted with $10 \% \mathrm{EtOH}-\mathrm{H}_{2} \mathrm{O}$; flow rate, $1.0 \mathrm{ml} / \mathrm{min}$; UV detection at $210 \mathrm{~nm}$.

\subsection{General procedure for O-acylation of phenols in $\mathrm{TfOH}$}

Phenol $(0.28 \mathrm{mmol})$ and acyl chloride $(0.84 \mathrm{mmol}$, 3eq) were dissolved in $1 \%$ TfOH- $\mathrm{CH}_{3} \mathrm{CN}(1 \mathrm{~mL})$ at room temperature. The reaction mixture was stirred at same temperature for an hour then poured into cold water and ethyl acetate. The organic layer was washed with $1 \mathrm{M} \mathrm{HCl}$, saturated $\mathrm{NaHCO}_{3}$ and saturated $\mathrm{NaCl}$, and dried over $\mathrm{MgSO}_{4}$, then filtrated. The filtrate was concentrated to afford $O$-acylated products. All spectral data was identical with the literatures. $^{27}$

\subsection{General procedure of Friedel-Crafts acylation of phenols in $\mathrm{TfOH}$}

Phenol $(0.28 \mathrm{mmol})$ and acyl chloride $(0.28 \mathrm{mmol})$ were dissolved in $\mathrm{TfOH}(3 \mathrm{~mL})$ at $0{ }^{\circ} \mathrm{C}$. The reaction mixture was warmed to room temperature for appropriate time in Table 2, then poured into cold water and ethyl acetate. The organic layer was washed with $1 \mathrm{M} \mathrm{HCl}$, saturated $\mathrm{NaHCO}_{3}$ and saturated $\mathrm{NaCl}$, and dried over $\mathrm{MgSO}_{4}$, then filtrated. The filtrate was concentrated and the residue was subjected silica column chromatography to afford acylated products. All spectral data was identical with the literatures. ${ }^{27}$

\subsection{General procedure of Fries rearrangement for O-acyloxy benzenes in $\mathrm{TfOH}$}

$O$-acyloxy benzenes $(0.28 \mathrm{mmol})$ were dissolved in TfOH (3 $\mathrm{mL}$ ) at $0{ }^{\circ} \mathrm{C}$. The reaction mixture was warmed to room temperature for appropriate time in Table 3, then poured into cold water and ethyl acetate. The organic layer was washed with $1 \mathrm{M} \mathrm{HCl}$, saturated $\mathrm{NaHCO}_{3}$ and saturated $\mathrm{NaCl}$, and dried over $\mathrm{MgSO}_{4}$, then filtrated. The filtrate was concentrated and the 
residue was subjected silica column chromatography to afford acylated products. All spectral data was identical with the literatures. ${ }^{26}$

\subsection{Synthesis of optical pure homotyrosine}

4.5.1. (S)- and (R)- 1-methyl 4-phenyl 2-(2,2,2trifluoroacetamido)succinate (12).

Phenol 1 (30 $\mu \mathrm{l}, 0.34 \mathrm{mmol})$ and $(S)-11(0.267 \mathrm{~g}, 1.02 \mathrm{mmol})$ were dissolved in $1 \mathrm{ml}$ of $1 \% \mathrm{TfOH}$ in $\mathrm{CH}_{3} \mathrm{CN}$ at $0{ }^{\circ} \mathrm{C}$. The reaction mixture was allowed to warm to room temperature and stirred for an hour, then poured into cold water and ethyl acetate. The organic layer was washed with saturated $\mathrm{NaHCO}_{3}$, saturated $\mathrm{NaCl}$ and dried over $\mathrm{MgSO}_{4}$, then filtrated. The filtrate was concentrated to afford (S)-12 (0.098 g, 91\%).

$(S)-12 \delta_{\mathrm{H}}\left(500 \mathrm{MHz}, \mathrm{CDCl}_{3}\right)$ 7.42-7.39 (3H, m), $7.26(1 \mathrm{H}, \mathrm{t}, J$ $7.4 \mathrm{~Hz}), 7.08(2 \mathrm{H}, \mathrm{d}, J 8.0 \mathrm{~Hz}), 4.96(1 \mathrm{H}, \mathrm{m}), 3.84(3 \mathrm{H}, \mathrm{s}, 3 \mathrm{H})$, $3.38(1 \mathrm{H}, \mathrm{dd}, J 17.8,4.0 \mathrm{~Hz}), 3.18(1 \mathrm{H}, \mathrm{dd}, J 17.5,4.3 \mathrm{~Hz}) . \delta_{\mathrm{C}}$ $\left(125 \mathrm{MHz}, \mathrm{CDCl}_{3}\right)$ 169.43, 169.30, $157.03\left(\mathrm{q},{ }^{2} J_{C F} 38.0 \mathrm{~Hz}\right)$, 129.60, 126.42, 121.21, 115.38 (q, $\left.{ }^{1} J_{C F} 300.3 \mathrm{~Hz}\right), 53.50,48.91$, 35.67. HRMS (ESI): $\mathrm{MH}^{+}$, found 320.0730. $\mathrm{C}_{13} \mathrm{H}_{13} \mathrm{~F}_{3} \mathrm{NO}_{5}$ requires 320.0746; $[\alpha]_{\mathrm{D}}+86.0\left(\mathrm{c} 1.0, \mathrm{CHCl}_{3}\right)$.

$(R)-\mathbf{1 2}$ was obtained from $(R)-\mathbf{1 1}$ with same manner for $(S)-\mathbf{1 2}$ (86\%). The $\delta_{\mathrm{H}}$ and $\delta_{\mathrm{c}}$ data for these samples were identical with these recorded for $(S)-12$. $[\alpha]_{\mathrm{D}}-86.0\left(\right.$ c $\left.1.0, \mathrm{CHCl}_{3}\right)$.

4.5.2. General procedure of Friedel-Crafts reaction for phenol 1 and N-TFA-Asp(Cl)-OMe 11 in TfOH

Phenol 1 (0.02 ml, $0.23 \mathrm{mmol})$ and $(S)-11$ (60.3 mg, 0.23 mmol) was dissolved in $\mathrm{TfOH}(1 \mathrm{ml})$ at $0{ }^{\circ} \mathrm{C}$. The reaction mixture was warmed to room temperature, maintained the temperature for an hour and poured into cold water and ethyl acetate. The organic layer was washed with $1 \mathrm{~N} \mathrm{HCl}, 5 \%$ $\mathrm{NaHCO}_{3}, 1 \mathrm{~N} \mathrm{HCl}$, and saturated $\mathrm{NaCl}$ successively, dried over $\mathrm{MgSO}_{4}$, filtrated and concentrated. The residue was subjected to silica column chromatography (ethyl acetate : hexane $=1: 2$ ) to afford pure (S)-13 and (S)-14 as colorless amorphous mass.

(S)-13 41\%; $v_{\max }$ (neat) 3300, 1714, 1663, $1600 \mathrm{~cm}^{-1} ; \delta_{\mathrm{H}}$ $\left(\mathrm{CDCl}_{3}\right) 7.85(2 \mathrm{H}, \mathrm{d}, J 8.6 \mathrm{~Hz}), 7.58(1 \mathrm{H}, \mathrm{d}, J 8.0 \mathrm{~Hz}), 6.89(2 \mathrm{H}$, d, $J 8.6 \mathrm{~Hz}), 4.97-4.93(1 \mathrm{H}, \mathrm{m}), 3.83(1 \mathrm{H}, \mathrm{dd}, J 18.3,4.0 \mathrm{~Hz})$, 3.79 (3H, s), 3.51 (1H, dd, $J 18.3,4.0 \mathrm{~Hz}) ; \delta_{\mathrm{C}}\left(\mathrm{CDCl}_{3}\right)$ 195.7, $170.2,161.2,157.0\left(\mathrm{q},{ }^{2} J_{C F}=38.0 \mathrm{~Hz}\right), 130.9,128.43,115.8(\mathrm{q}$, $\left.{ }^{1} J_{C F}=287.5 \mathrm{~Hz}\right), 115.6,53.3,48.7,39.3$; HRMS (ESI): $\mathrm{MH}^{+}$, found 320.0751. $\mathrm{C}_{13} \mathrm{H}_{13} \mathrm{~F}_{3} \mathrm{NO}_{5}$ requires 320.0746; $[\alpha]_{\mathrm{D}}+75.0$ (c 1.0, $\mathrm{CHCl}_{3}$ ).

(S)-14 38\%; $v_{\max }$ (neat) 3300, 1720, 1640, $1580 \mathrm{~cm}^{-1} ; \delta_{\mathrm{H}}$ $\left(500 \mathrm{MHz}, \mathrm{CDCl}_{3}\right) 7.70(1 \mathrm{H}, \mathrm{d}, J 8.0 \mathrm{~Hz}), 7.53(1 \mathrm{H}, \mathrm{t}, J 8.0 \mathrm{~Hz})$, $7.44(1 \mathrm{H}, \mathrm{d}, J 6.9 \mathrm{~Hz}), 7.01(1 \mathrm{H}, \mathrm{d}, J 8.6 \mathrm{~Hz}), 6.95(1 \mathrm{H}, \mathrm{t}, \mathrm{J}=7.4$ $\mathrm{Hz}), 4.96(1 \mathrm{H}, \mathrm{m}), 3.90(1 \mathrm{H}, \mathrm{dd}, J 18.3,4.0 \mathrm{~Hz}), 3.81(3 \mathrm{H}, \mathrm{s})$, $3.68(1 \mathrm{H}, \mathrm{dd}, J 18.3,4.0 \mathrm{~Hz}) ; \delta_{\mathrm{C}}\left(125 \mathrm{MHz}, \mathrm{CDCl}_{3}\right) 202.56$, $169.72,162.45,156.98$ (q, $\left.{ }^{2} J_{C F} 38.0 \mathrm{~Hz}\right), 137.49,129.80,119.44$, 118.75, 118.59, 115.50 (q, ${ }^{1} J_{C F} 287.5 \mathrm{~Hz}$ ), 53.32, 48.29, 39.41; HRMS (ESI): $\mathrm{MH}^{+}$, found 320.0749. $\mathrm{C}_{13} \mathrm{H}_{13} \mathrm{~F}_{3} \mathrm{NO}_{5}$ requires 320.0746; $[\alpha]_{\mathrm{D}}+107.0$ (c 1.0, $\mathrm{CHCl}_{3}$ ).

$(R)-13$ and $(R)-14$ were prepared with identical manner described above started from $(R)-\mathbf{1 1}$. The $\delta_{\mathrm{H}}$ and $\delta_{\mathrm{C}}$ data for these samples were identical with these recorded for (S)-13 and (S)-14.

(R)-13, 40\%, $[\alpha]_{\mathrm{D}}-74.0$ (c 1.0, $\mathrm{CHCl}_{3}$ ).

$(R)-14,39 \%,[\alpha]_{D}-108.0\left(\right.$ c $\left.1.0, \mathrm{CHCl}_{3}\right)$.
4.5.3. General procedure of Fries rearrangement in $\mathrm{TfOH}$

Compound (S)-12 (1.008 g, $3.15 \mathrm{mmol})$ was dissolved in $\mathrm{TfOH}(5 \mathrm{ml})$ at $0{ }^{\circ} \mathrm{C}$ and warmed to room temperature. The reaction mixture was stirred for 16 hours and poured into cold water and ethyl acetate. The organic layer was treated with same manner described for Friedel-Crafts reaction to afford (S)-13 (0.483 g, 48\%) and (S)-14 (0.360 g, 36\%). Analytical data of each isomer was identical with the Friedel-Crafts products.

$(R)-\mathbf{1 3}$ and $(R)-\mathbf{1 4}$ were prepared with identical manner described above started from $(R)-12((R)-13$ 45\%, $(R)-1433 \%)$. Analytical data of each isomer was identical with the FriedelCrafts products.

\subsubsection{General procedure for benzylic carbonyl reduction}

Compound (S)-13 (0.170 g, $0.53 \mathrm{mmol})$ and $\mathrm{Pd} / \mathrm{C}$ (10\%, 30 $\mathrm{mg}$ ) were suspended in acetic acid $(10 \mathrm{ml})$. The reaction mixture was stirred under hydrogen atmosphere for an hour, and then filtrated with Celite. The filtrate was concentrated and the residue was subjected to silica column chromatography (ethyl acetate : hexane $=1: 2$ ) to afford (S)-15 as amorphous mass. (0.157 g, 97\%)

(S)-15; $v_{\max }$ (neat) 3350, 1720, $1595 \mathrm{~cm}^{-1} ; \delta_{\mathrm{H}}(500 \mathrm{MHz}$, $\left.\mathrm{CDCl}_{3}\right) 7.03(2 \mathrm{H}, \mathrm{d}, J 8.6 \mathrm{~Hz}), 6.83(1 \mathrm{H}, \mathrm{d}, J 6.3 \mathrm{~Hz}), 6.77(2 \mathrm{H}, \mathrm{d}$, $J$ 8.6 Hz), 4.67-4.64 (1H, m), $3.77(3 \mathrm{H}, \mathrm{s}), 2.61-2.58(2 \mathrm{H}, \mathrm{m})$, 2.27-2.24 $(1 \mathrm{H}, \mathrm{m}), 2.12-2.05(1 \mathrm{H}, \mathrm{m}) ; \delta_{\mathrm{C}}\left(125 \mathrm{MHz}, \mathrm{CDCl}_{3}\right)$ $171.40,156.90\left(\mathrm{q},{ }^{2} J_{C F} 37.6 \mathrm{~Hz}\right), 154.29,131.58,129.41,115.53$ (q, $\left.{ }^{1} J_{C F} 287.9 \mathrm{~Hz}\right), 115.45,52.96,52.37,33.33,30.39$; HRMS (ESI): $\mathrm{MH}^{+}$, found 306.0960. $\mathrm{C}_{13} \mathrm{H}_{15} \mathrm{~F}_{3} \mathrm{NO}_{4}$ requires 306.0953; $[\alpha]_{\mathrm{D}}+39.0\left(\mathrm{c} 1.0, \mathrm{CHCl}_{3}\right)$

(S)-16 was obtained from (S)-14 with same manner of (S)-13.

(S)-16 86\%; $v_{\max }$ (neat) 3320, 1720, $1550 \mathrm{~cm}^{-1} ; \delta_{\mathrm{H}}(500 \mathrm{MHz}$, $\left.\mathrm{CDCl}_{3}\right) 7.23(1 \mathrm{H}, \mathrm{d}, J 6.9 \mathrm{~Hz}), 7.10-7.09(2 \mathrm{H}, \mathrm{m}), 6.88(1 \mathrm{H}, \mathrm{t}, J$ $7.4 \mathrm{~Hz}), 6.74(1 \mathrm{H}, \mathrm{d}, J 8.0 \mathrm{~Hz}), 4.67-4.66(1 \mathrm{H}, \mathrm{m}), 3.68(3 \mathrm{H}, \mathrm{s})$, 2.72-2.67 (2H, m), 2.35-2.26 $(1 \mathrm{H}, \mathrm{m}), 2.19-2.16(1 \mathrm{H}, \mathrm{m}) ; \delta_{\mathrm{C}}$ $\left(125 \mathrm{MHz}, \mathrm{CDCl}_{3}\right) 171.38,157.12\left(\mathrm{q},{ }^{2} J_{C F} 37.6 \mathrm{~Hz}\right), 153.52$, 130.52, 127.93, 126.11, 120.97, 115.68 (q, $\left.{ }^{1} J_{C F} 287.5 \mathrm{~Hz}\right)$, 115.45, 52.87, 52.37, 31.35, 25.36; $[\alpha]_{\mathrm{D}}+44.0$ (с 1.0, $\mathrm{CHCl}_{3}$ ).

$(R)$-15 and (R)- 16 were prepared with identical manner described above started corresponding precursors. The $\delta_{\mathrm{H}}$ and $\delta_{\mathrm{C}}$ for these samples were identical with these recorded for (S)-15 and $(S)-16$.

(R)-15, 99\%, $[\alpha]_{\mathrm{D}}-38.5$ (c 1.0, $\mathrm{CHCl}_{3}$ ).

(R)-16, 87\%, $[\alpha]_{\mathrm{D}}-44.0$ (c 1.0, $\left.\mathrm{CHCl}_{3}\right)$

\subsubsection{General procedure for deprotection}

Compound (S)-15 (0.152 g, $0.50 \mathrm{mmol})$ was dissolved in 6M $\mathrm{HCl}(2 \mathrm{ml})$. The reaction mixture was heated at $80^{\circ} \mathrm{C}$ for 6 hours, then concentrated. The residue was subjected to silica column chromatography $\left(\mathrm{CH}_{3} \mathrm{CN}: \mathrm{MeOH}: \mathrm{H}_{2} \mathrm{O}=4: 1: 1\right)$ to afford (S)-17 as colorless amorphous mass (0.103 g, 90\%).

(S)-17; $v_{\max }$ (neat) $3100,1740 \mathrm{~cm}^{-1} ; \mathrm{mp} 217-220{ }^{\circ} \mathrm{C} ; \delta_{\mathrm{H}}$ (500MHz, CD 3 OD) $7.06(2 \mathrm{H}, \mathrm{d}, J 8.6 \mathrm{~Hz}), 6.73(2 \mathrm{H}, \mathrm{d}, J 8.6 \mathrm{~Hz})$, $3.95(1 \mathrm{H}, \mathrm{t}, J 6.3 \mathrm{~Hz}), 2.75-2.63(2 \mathrm{H}, \mathrm{m}), 2.22-2.18(1 \mathrm{H}, \mathrm{m})$, 2.13-2.06 $(1 \mathrm{H}, \mathrm{m}) ; \delta_{\mathrm{C}}\left(125 \mathrm{MHz}, \mathrm{CD}_{3} \mathrm{OD}\right) 171.78,157.05,131.90$, 130.36, 116.41, 53.44, 33.92, 31.23; HRMS (ESI): $\mathrm{MH}^{+}$, found 
196.0958. $\mathrm{C}_{10} \mathrm{H}_{14} \mathrm{NO}_{3}$ requires 196.0974; $[\alpha]_{\mathrm{D}}+35.6$ (с 1.0, $\mathrm{CHCl}_{3}$ ); chiral HPLC $t_{\mathrm{R}}=6.78 \mathrm{~min}$.

(S)-18 95\%; $v_{\max }$ (neat) 3350, 3100, $1750 \mathrm{~cm}^{-1}$; mp 194$196{ }^{\circ} \mathrm{C} ; \delta_{\mathrm{H}}\left(500 \mathrm{MHz}, \mathrm{CD}_{3} \mathrm{OH}\right) 7.11(1 \mathrm{H}, \mathrm{d}, J 7.4 \mathrm{~Hz}), 7.06(1 \mathrm{H}, \mathrm{t}$, $J$ 7.7 Hz), 6.80-6.77 (2H, m), $3.91(1 \mathrm{H}, \mathrm{t}, J 6.3 \mathrm{~Hz}), 2.85-2.82$ $(1 \mathrm{H}, \mathrm{m}), 2.75-2.69(1 \mathrm{H}, \mathrm{m}), 2.27-2.10(2 \mathrm{H}, \mathrm{m}) ; \delta_{\mathrm{C}}(125 \mathrm{MHz}$, $\left.\mathrm{CD}_{3} \mathrm{OD}\right)$ 172.82, 157.21, 132.16, 129.77, 128.20, 121.78, 116.90, 54.55, 32.96, 27.77; $[\alpha]_{\mathrm{D}}+27.3\left(\mathrm{c} 1.0, \mathrm{CHCl}_{3}\right)$; chiral HPLC $t_{\mathrm{R}}=$ $7.34 \mathrm{~min}$

$(R)-17$ and $(R)-18$ The $\delta_{\mathrm{H}}$ and $\delta_{\mathrm{C}}$ NMR for these samples were identical with these recorded for (S)-17 and (S)-18.

$(R)-17,97 \%,[\alpha]_{\mathrm{D}}-34.5(\mathrm{c} 1.0,1 \mathrm{~N} \mathrm{HCl})$. chiral HPLC $t_{\mathrm{R}}=$ 8.59 min. $(R)-18,96 \%,[\alpha]_{\mathrm{D}}-29.5(\mathrm{c} 1.0,1 \mathrm{~N} \mathrm{HCl})$. chiral HPLC $t_{\mathrm{R}}=9.35 \mathrm{~min}$.

\section{Acknowledgments}

We are very grateful to Professor G. D. Holman (University of Bath, U.K.) for valuable advice throughout the manuscript.This research was partially supported by Ministry of Education, Science, Sports and Culture Grant-in-Aid for Scientific Research on a Priority Area, 18032007, for Scientific Research on Innovative Areas, 20200038 and for Scientific Research (C), 19510210, 21510219.)

\section{References and notes}

1. (a) Martin, R. Org. Prep. Proced. Int. 1992, 24, 369-435; (b) Olah, G. A. In Friedel-Crafts and Related Reactions, WileyInterscience, New York and London, 1963-1964, Vol. I-IV.

2. Olah, G. A.; Prahash, G. K. S.; Sommer, J. In Superacids, Wiley, New York, 1985.

3. Olah, G. A.; Prahash, G. K. S.; Sommer, J. Science 1979, 206, 13-20.

4. Kobayashi, S.; Sugiura, M.; Kitagawa, H.; Lam, W. W. L. Chem. Rev. 2002, 102, 2227-2302.

5. (a) Murashige, R.; Hayashi, Y.; Hashimoto, M. Tetrahedron Lett. 2008, 49, 6566-6568; (b) Murai, Y.; Hatanaka, Y.; Kanaoka, Y.; Hashimoto, M. Heterocycles 2009, 79, 359-364; (c) Murashige, R.; Murai, Y.; Hatanaka, Y.; Hashimoto, M. Biosci. Biotechnol. Biochem., 2009, 73, 1377-1380.

6. (a) Okumura, H. S.; Philmus, B.; Portmann, C.; Hemscheidt, T. K. J. Nat. Prod. 2009, 72, 172-176; (b) Plaza, A.; Bewley, C. A. J. Org. Chem. 2006, 71, 6898-6907.

7. Canesi, S.; Bouchu, D.; Ciufolini, M. A. Angew. Chem. Int. Ed. 2004, 43, 4336-4338.

8. Wang, D.; Cole, P. A. J. Am. Chem. Soc. 2001, 123, 8883-8886.

9. Evans, W. C.; Walker, N. J. Chem. Soc. 1947, 1571-1573.

10. Barfoot, C. W.; Harvey, J. E.; Kenworthy, M. N.; Kilburn, J. P.; Ahmed, M.; Taylor, R. J. K. Tetrahedron, 2005, 61, 3403-3417.
11. Yamada, M.; Nagashima, N.; Hasegawa, J.; Takahashi, S. Tetrahedron Lett. 1998, 39, 9019-9022.

12. Xie, Y.; Lou, R.; Li, Z.; Mi, A.; Jiang, Y. Tetrahedron: Asymm. 2000, 11, 1487-1494.

13. Brea, R. J.; López-Deber, M. P.; Castedo, L.; Granja, J. R. J. Org. Chem. 2006, 71, 7870-7873.

14. (a) Reifenrath, W. G.; Bertelli, D. J.; Micklus, M. J.; Fries, D. S Tetrahedron Lett. 1976, 17, 1959-1962; (b) Nordlander, J. E. Payne, M. J.; Njoroge, F. G.; Vishwanath, V. M.; Han, G. R.; Laikos, G. D.; Balk, M. A. J. Org. Chem. 1985, 50, 3619-3622; (c) Melillo, D. G.; Larsen, R. D.; Mathre, D. J.; Shukis, W. F.; Wood, A. W.; Colleluori, J. R. J. Org. Chem. 1987, 52, 51435150; (d) Griesbeck, A. G.; Heckroth, H. Synlett 1997, 1243-1244; (e) Lin, W.; He, Z.; Zhang, H.; Zhang, X.; Mi, A.; Jiang, Y. Synthesis 2001, 1007-1009; (f) Xu, Q.; Wang, G.; Wang, X.; Wu, T.; Pan, X.; Chan, A. S. C.; Yang, T.; Tetrahedron: Asymm. 2000, 11, 2309-2314.

15. Dumeunier, R.; Markó, I. E. Tetrahedron Lett. 2004, 45, 825-829.

16. Kobayashi, S.; Moriwaki, M.; Hachiya, I. Tetrahedron Lett. 1996, 37, 2053-2056.

17. (a) Kaboudin B. Tetrahedron 1999, 55, 12865-12872; (b) Mouhtady, O.; Gaspard-Iloughmane, H.; Roques, N.; Rouxa, C. L. Tetrahedron Lett. 2003, 44, 6379-6382.

18. Roberts, R. M. G.; Sadri, A. R.; Tetrahedron 1983, 39, 137-42.

19. Sharghi, H.; Hosseini-Sarvari, M.; Eskandari, R.; Synthesis 2006, 2047-2052.

20. Weygand, F.; Klinke, P.; Eigen, I. Chem. Ber. 1957, 90, 18961905.

21. Ruth, W. Acta Chem. Scand. 1954, 8, 1542-1546.

22. Effenberger, F.; Eberhard, J. K.; Maier A. H. J. Am. Chem. Soc. 1996, 118, 12572-12579.

23. Booth, B. L.; Haszeldine, R. N.; Laali, K. J. Chem. Soc. Perkin Trans. 1 1980, 2887-2893.

24. (a) Effenberger, F.; Epple, G. Angew. Chem., Int. Ed. Engl. 1972, 11, 299-300; (b) Effenberger, F.; Epple, G. Angew. Chem., Int. Ed. Engl. 1972, 11, 300-301.

25. Krawczyk, H.; Albrecht, L.; Wojciechowski, J.; Wolf, W. M. Tetrahedron 2007, 63, 12583-12594.

26. Matsushita, Y.; Sugamoto, K.; Matsui, T. Tetrahedron Lett. 2004, 45, 4723-4727.

27. (a) Lota, R. K.; Olusanjo, M. S.; Dhanani, S.; Owen, C. P.; Ahmed, S. J. Steroid Biochem. Mol. Biol. 2008, 111, 128-137; (b) Park, K. K.; Jeong, J. Tetrahedron 2005, 61, 545-553; (c) Armstrong, E. C.; Bent, R. L.; Loria, A.; Thirtle, J. R.; Weissberger, A.; J. Am. Chem. Soc., 1960, 82, 1928-1935; (d) Fischer, A.; Henderson, G. N.; Thompson, R. J. Aust. J. Chem., 1978, 31, 1241-1247; (e) Gu, W.; Hill, A. J.; Wang, X.; Cui, C.; Weiss, R. G. Macromolecules 2000, 33, 7801-7811; (f) Montiel-Smith, S.; Meza-Reyes, S.; Viñas-Bravo, O.; Fernández-Herrera, M. A.; Martínez-Pascual, R.; Sandoval-Ramírez, J.; Fuente, A.; Reyes, M.; Ruiz, J. A. ARKIVOC 2005, 127-135; (g) Liu, Z.; Sun, Y.; Wang, J.; Zhu, H.; Zhou, H.; Hu, J.; Wang, J. Sep. Purif. Technol. 2008, 64, 247-252; (h) Park, K. K.; Lee, H. J.; Kim, E. H.; Kang, S. K. J. Photochem. Photobiol. A: Chem. 2003, 159, 17-21. 